Nr $256 \bullet 1996$

The effects of a mobile telephone task on driver behaviour in a car following situation

Håkan Alm and Lena Nilsson

Reprint from Accident Analysis and Prevention, Vol. 27, No 5, pp. 707-715, 1995

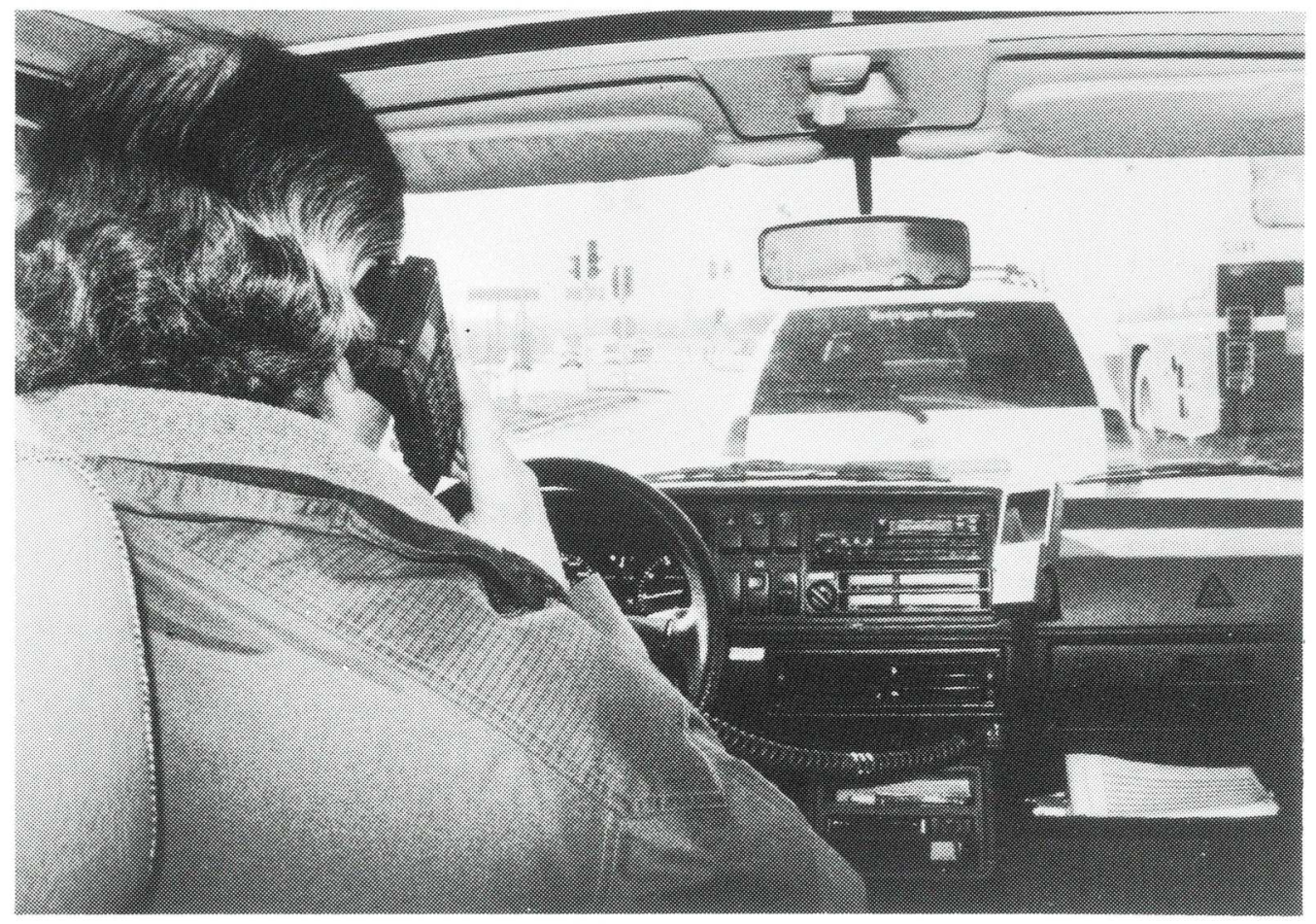

ats 


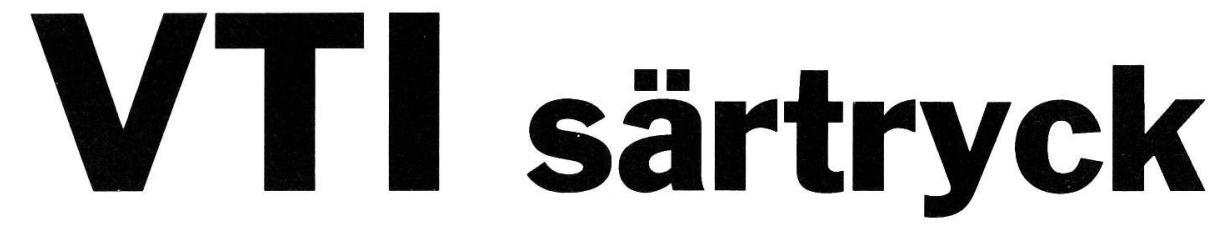

Nr $256 \bullet 1996$

The effects of a mobile telephone task on driver behaviour in a car following situation Håkan Alm and Lena Nilsson

Reprint from Accident Analysis and Prevention, Vol. 27, No 5, pp. 707-715, 1995 


\title{
THE EFFECTS OF A MOBILE TELEPHONE TASK ON DRIVER BEHAVIOUR IN A CAR FOLLOWING SITUATION
}

\author{
HÅKAN ALM* and LENA NiLSSON \\ Swedish Road and Transport Research Institute (VTI), S-581 95 Linköping, Sweden \\ (Received 25 February 1995; Accepted 12 April 1995)
}

\begin{abstract}
The effects of a mobile telephone task on young and elderly drivers' choice reaction time, headway, lateral position, and workload were studied when the subjects were driving in a car-following situation, in the VTI driving simulator. It was found that a mobile telephone task had a negative effect upon the drivers' choice reaction time, and that the effect was more pronounced for the elderly drivers. Furthermore, the subjects did not compensate for their increased reaction time by increasing their headway during the phone task. The subjects' mental workload, as measured by the NASA-TLX, increased as a function of the mobile telephone task. No effect on the subjects' lateral position could be detected. Taken together, these results indicate that the accident risk can increase when a driver is using the mobile telephone in a car following situation. The reasons for the increased risk, and possible ways to eliminate it, are also discussed.
\end{abstract}

\section{INTRODUCTION}

In a recent study (Alm and Nilsson 1994), the effect of being engaged in a mobile telephone task while driving was studied with the help of an advanced driving simulator. It was found that a mobile telephone task had a negative effect on drivers' simple reaction time and led to a reduction of speed, when the tracking demands of the driving task were low. The telephone task also had an effect on drivers' lane position, most pronounced when the tracking demands of the driving task were high. Finally, it led to an increased mental workload for the driving task with high, as well as low tracking demands. Some of these changes in driver behaviour may increase the risk of an accident. An unexpected reduction in speed level may, under some circumstances, lead to a rearend collision (Evans 1991). An increased reaction time, and extreme levels of workload, may also under some conditions, increase the risk of an accident. The results referred to above were found for a driving task that did not involve any interaction with other road users. The subjects in the study were driving on either a straight, or a curvy road, where no other road users were present. Furthermore, they knew in advance that only one critical event could occur during the experiment, and there was only one action to perform when the critical event occurred. Situations

\footnotetext{
*To whom all correspondence should be addressed.
}

with these general characteristics exist in real life, but are only one sample of possible, and fairly simple traffic situations. To increase our knowledge concerning the effects of mobile telephone use on driver behaviour, it is necessary to take samples of other relevant traffic situations. In most situations a driver has to interact with other road users. Some important aspects of the interaction between road users involve interpretation and prediction of other road users' behaviour. One common situation, involving interaction between road users, is a car following situation. A driver following another car has to interpret and predict the behaviour of the lead vehicle, and as a result of the prediction, choose a headway to the lead vehicle. An interesting study by Evans and Wasielewski (1982) showed a correlation between traffic safety and a drivers choice of headway, in a car following situation. In the study observations were made of time headway's for drivers travelling on a local freeway during rush hours. Using records of accident involvement, Evans and Wasielevski found that accident involved drivers were more likely to follow other cars with time headway's of $<1 \mathrm{sec}$, compared to accident free drivers. One implication of the study is that the size of a drivers headway, to some extent, can be used as a predictor of accident involvement.

A driver's headway may be influenced by mobile telephone use in a number of possible ways. Firstly, the handling aspects of the mobile telephone may 
interfere with the driver's visual scanning of the traffic environment, and also with some actions used to control the vehicle. The effect may be that the driver does not detect a sudden change in behaviour of a lead vehicle, detects it late, cannot perform, or has problems to perform a suitable action. Secondly, the increase in workload due to the telephone use (Alm and Nilsson 1994) may interfere with the driver's ability to attend to and interpret relevant information from the traffic scene. On the other hand, it can be argued that drivers are aware of the dangers associated with telephone use during driving, and therefore will compensate for the increased risk. In a car following situation this can be done by increasing the headway to the lead vehicle. Alternatively, a driver may avoid allocating large processing resources to the telephone task and instead concentrate most of the resources to the driving task.

The aim of this following study was to investigate whether the effects on reaction time, mental workload, and lateral position found in the earlier study by Alm and Nilsson (1994) would also be found in a driving task where the subjects must interact with other road users. Another aim was to investigate whether the telephone task had an effect on the subjects choice of headway. If the telephone task has a negative effect on the subjects reaction time, would the subjects compensate by an increased headway? The following predictions were made. Firstly, it was predicted that the drivers' reaction time would be negatively affected by a mobile telephone task. Secondly, it was predicted that the subjects would not compensate for the increased reaction time by increasing their headway. The reason for this prediction was that the mobile telephone is a rather new in-car device, and that general knowledge concerning negative side effects seem to be lacking. Not knowing that it may have a negative impact on the ability to react quickly, there is no reason to compensate by increasing the headway. Besides, many drivers also seem to overestimate their driving ability (Svenson 1981) and will probably not realize the need to be extra careful when using the telephone during driving. Thirdly, it was predicted that a mobile telephone task would have a negative impact on drivers' ability to follow the road in an optimal way, and as a consequence lead to an increase in variation in lateral position. Fourthly, it was predicted that the drivers' workload would increase as a result of the telephone task.

\section{METHOD}

\section{Subject}

Forty subjects, 30 men and 10 women, participated in the study. The subjects were divided into two groups, younger drivers $(<60$ years of age, mean age 29.3 , standard deviation 8.1 years), and elderly drivers ( $\geq 60$ years of age, mean age 67.6 , standard deviation 4.1 years). All subjects had a driving license, and were experienced drivers meaning that they had had their driving license for at least 5 years, and that they were driving at least $10,000 \mathrm{~km}$ per year. The subjects were recruited via advertisements at various public places. They were paid (250 SEK, about U.S.\$32) for their participation in the experiment. The subjects were randomly assigned to four experimental conditions.

\section{Apparatus}

The VTI driving simulator was used for the study. It is an advanced simulator which consists of a moving base system, a wide angle visual system, a vibration-generating system, a sound system, and a temperature-regulating system (Nordmark et al. 1986; Nordmark et al. 1988; Nilsson 1989). These five subsystems can be controlled to operate in a way that gives the driver an impression of real driving.

\section{Tasks}

The road type that was presented to the subjects in the simulator was a two-lane, 7-m wide, rather straight, asphalt road. The road surface was characterized by high friction, corresponding to a dry summer road, and the visibility condition was similar to a cloudy, slightly hazy, summer day with a visibility of approx. $400 \mathrm{~m}$. Two different routes, one practice route and one test route, were used in the experiment. The practice route was $20 \mathrm{~km}$ long, rather straight and easy to drive. The test route was $80 \mathrm{~km}$ long. It was also rather straight, and was not expected to cause the subjects any problems to follow the road.

\section{Other vehicles}

When driving, the subjects met a continuous stream of on-coming vehicles, equivalent to a flow of 600 vehicles/hr. The distance between each vehicle in the opposite lane was always $150 \mathrm{~m}$, and they drove with a constant speed of $90 \mathrm{~km} / \mathrm{hr}$. Each subject was also forced into a car following situation 16 times during an experimental session. The start of a car following situation was defined as a situation where the distance between the front of the drivers car and the end of the lead vehicle, or headway, was equal to $75 \mathrm{~m}$. The location of these car following situations were randomly distributed over the $80 \mathrm{~km}$ distance, with the restriction that the minimum distance between them should be $3000 \mathrm{~m}$. To arrange for all subjects to start each car following situation at the same distances from the starting point, the behaviour of the lead vehicles was made dependent on the speed level of each subjects vehicle. Thus, each subject could 
drive with the speed level she or he preferred, and still start a car following situation at the same distances from the starting point as all other subjects.

\section{Vehicle}

The car body used in the experiment was an ordinary Saab 9000 with a manual gearbox. The simulated physical environment in the "car" corresponded to that in modern passenger cars. Thus, the noise level, the infra sound level, and the vibration level were all within the respective intervals for modern passenger cars during driving in real traffic. The thermal environment was according to normal indoor climate $\left(20^{\circ} \mathrm{C}\right)$.

\section{Mobile telephone}

The mobile telephone used was an Ericsson Hot Line device with handsfree facility (Ericsson Radio Systems AB, Sweden). It was mounted over the ventilation controls, on the instrument panel, to the right of the steering wheel. The mobile telephone was connected to two tape recorders. When a subject answered the telephone by pressing a button, one of the tape recorders was activated and presented the telephone task to the subject. Tasks for eight telephone calls were pre-recorded and presented by one of the tape recorders. The presented telephone tasks, together with the subjects' answers, were recorded on the second tape recorder.

\section{Telephone task}

The Working Memory Span Test (Baddeley et al. 1985) was chosen as the telephone task. This test contains a working memory part and a decision part. The subjects in the experimental groups were exposed to a number of sentences. Each sentence had the form " $X$ does $Y$ ", and contained three to five words. For instance: "The boy brushed his teeth" and "The train bought a newspaper". After each sentence the subjects were supposed to answer "yes" if the sentence was sensible, and "no" if it was nonsense. The test contained 50\% sensible and 50\% nonsense sentences. When five sentences had been presented, the subjects were required to recall the last word in each sentence, in the order they had been presented. During the experiment this procedure was repeated eight times for the experimental groups, each time with different sentences. Each telephone task started with an instruction, telling the subjects how to perform the task, followed by the presentation of five sentences. Each presentation took roughly $60 \mathrm{sec}$.

\section{Telephone calls in relation to a vehicle in front}

All subjects, in experimental as well as control groups, were forced into a car following situation 16 times during the experiment. The subjects in the experimental groups were exposed to a telephone task in eight of these car following situations. To avoid, as much as possible, correct anticipation of whether a telephone task would be presented or not when a car following situation started, there was an equal probability that the subjects in the experimental groups would, or would not, be exposed to a telephone task. Thus, in $50 \%$ (8) of the car following situations, a telephone task was presented. These telephone tasks were randomized over the 16 car following situations. The subjects in the control groups did, of course, not receive any telephone tasks.

To avoid, as much as possible, correct anticipation of what would happen when a telephone task was presented, there was an equal probability that something safety critical, or not safety critical would happen during the presentation. Thus, during the eight telephone tasks, four situations occurred when something safety critical happened, and four situations when something not safety critical happened. The order of presentation of these safety critical and not safety critical situations was randomized.

The four situations when something safety critical happened consisted of situations where the lead vehicle braked, with a deceleration of $4 \mathrm{~m} / \mathrm{sec}^{2}$ for a period of $5 \mathrm{sec}$, or until the speed level was $50 \mathrm{~km} / \mathrm{hr}$. After braking the lead vehicle accelerated with an acceleration of $3 \mathrm{~m} / \mathrm{sec}^{2}$ until it reached $90 \mathrm{~km} / \mathrm{hr}$. Ninety seconds after the start of the car following situation the lead vehicle indicated a right turn and left the road.

The four situations where something not safety critical happened consisted of situations where the lead vehicle indicated a right turn, by blinking for $5 \mathrm{sec}$, but did not change its speed level, nor its lateral position. Ninety seconds after the start of the car following situation the lead vehicle indicated a right turn and left the road.

To make it hard to anticipate when something safety critical or not safety critical would happen during a telephone task, the time interval between the start of the car following situation, and the occurrence of either blinking or braking events was varied in two steps, either 1 or $35 \mathrm{sec}$. The order in which these time intervals were used was randomized.

In all cases of either blinking or braking lead vehicles, the headway between the lead vehicle and the subjects vehicle was kept at a constant size of $75 \mathrm{~m}$, by adjusting the speed of the lead vehicle to the speed of the subject, until the lead vehicle either started to blink or brake. This was made in order to have control over the starting point for each subject, and make sure that all subjects had the same chance 
to detect the brake lights or direction indicators of the lead vehicle.

The eight situations where the lead vehicle did not signal anything were situations where the lead vehicle drove with a constant speed level in front of the driver, for a time period of $45 \mathrm{sec}$. After that the lead vehicle indicated an exit (by blinking for a duration of $5 \mathrm{sec}$ ) and left the road.

\section{Performance measures}

Choice reaction time was used as a measure in the four situations, for both experimental and control groups, where the lead vehicle braked. It was defined as the time it took the subjects to initiate a braking manoeuvre in response to the braking manoeuvre from the lead vehicle. Reaction time was sampled with a frequency of $50 \mathrm{~Hz}$.

Headway, defined as the distance (in metres) between the front of the subjects car and the end of the lead vehicle. Headway was only measured in the situations where the lead vehicle braked, and only for the time period when the subjects could control their headway, that is from the moment the lead vehicle started to brake. The sampling frequency for headway was $2 \mathrm{~Hz}$.

Lateral position, was measured in relation to a zero position, defined as the position where the central line of the road coincides with the central line through the drivers body. Lateral position was also measured with a sampling frequency of $2 \mathrm{~Hz}$. Lateral position was measured during the time a telephone task was received.

Subjective measures. To measure the subjects' workload a simplified version of the NASA-TLX rating scale, called RTLX (Hart and Staveland 1988; Byers et al. 1989) was used.

Communication measures. To measure the subjects performance on the telephone task, the number of correct sentence judgements (sensible/nonsense) were used as a measure of the decision part of the telephone task. For the working memory part of the telephone task the number of correctly recalled last words, in the order they were presented, was used as a measure.

Design. The study was performed as a two by two factorial design, where one factor concerned the age of the subjects (younger vs elderly), and the other factor the RTI system used (mobile telephone vs control).

\section{Procedure}

The subjects were randomly assigned to the experimental or control conditions, and given a written instruction describing their task. The subjects in the experimental groups were told that they were supposed to drive an $80 \mathrm{~km}$ long route in the simulator. They were asked to drive in the way they normally are driving a real car on a road with a speed limit of $90 \mathrm{~km} / \mathrm{hr}$, and to avoid playing with it. They were also instructed to brake with their right foot. The subjects were told that during driving they would catch up with a number of vehicles, and that one of three things could happen. The vehicle in front could just go on for a while, and thereafter leave the road. It could also give an indication with its right blinker, or brake suddenly. As a response to the right blinker the subjects were told to make an indication with their own left blinker, and as a response to the braking manoeuvre the subjects were told to brake as fast as possible, with their right foot. They were also told that the mobile telephone would ring a number of times. The subjects were instructed to answer by pushing the button for the handsfree function, listen to the instructions, and solve the task presented over the telephone. The subjects in the experimental groups were given training on the telephone task. They practised on four tasks of varying difficulty (one, two, three, and four sentences, respectively) sitting at a table. The subjects in the control groups were exposed to an identical instruction, but without the part containing the mobile telephone. In the next phase, all subjects were introduced to the driving simulator. For the experimental groups the handling aspects of the mobile telephone were repeated, and they could practice to locate and push the button for the handsfree function. Thereafter, all subjects drove a $20 \mathrm{~km}$ long practice route. All subjects caught up a number of vehicles during the practice drive. They could then practice to make an indication with the left blinker, brake, or do nothing but drive. For the subjects in the experimental groups the mobile telephone also rang three times, and the subjects could practice to solve the same telephone tasks as they did before (sitting by the table), but now via the mobile telephone and while driving. During the training phase the experiment leader could assist the subjects in the learning of the task. When the training phase was over, all subjects had a short break. After the $80 \mathrm{~km}$ long test route each subject had to complete the NASA RTLX. Finally the subjects were thanked for their participation in the study, and paid 250 SEK (about U.S.\$32). The running of a subject took $1.5-2.0 \mathrm{hr}$ in total.

\section{RESULTS}

The results are based on complete data from 40 subjects, 10 subjects in each condition. During the experimental session two subjects reported "simulator sickness", and were replaced. The following results will be presented: The subjects' choice reaction time, 
headway/safety margin, lateral position during the telephone call, workload, and performance on the telephone task.

\section{Choice reaction time}

It was predicted that the subjects in the experimental groups should have a longer reaction time compared to the subjects in the control groups. Figure 1 shows the results relevant for this prediction.

From Fig. 1 we can see that the subjects in the experimental groups had a longer reaction time compared to the subjects in the control groups. A twoway ANOVA showed a significant main effect of experimental condition $F(1,35)=9.36, p=0.0042$, and of AGE, $F(1,35)=6.06, p=0.0189$. The difference in reaction time for young subjects in experimental and control groups was $0.56 \mathrm{sec}$. The corresponding value for elderly subjects was $1.46 \mathrm{sec}$. Thus the prediction was fully supported.

\section{Headway}

It was predicted that the subjects should not compensate for their increased reaction time by increasing their headway. The minimum, maximum and average values were used as different measures of the subjects' headway. These measures were recorded from the moment the subjects could control their headway freely, i.e. after they had been exposed to a braking manoeuvre from the car in front of them. To avoid effects on headway caused only by differences in reaction time, the first five seconds of the time the subjects could control their headway freely, was disregarded. Minimum, maximum, and average headways were calculated as a mean value for each subject, summarized over all four braking events.

\section{Minimum headway}

Figure 2 shows the relevant results concerning the subjects' minimum headway.

From Fig. 2 we can see that the subjects in the experimental groups had a shorter minimum headway compared to the subjects in the control groups. A two way ANOVA showed significant effects of experimental condition, $F(1,36)=4.21, p=0.04$, and of AGE, $F(1,36)=6.27, p=0.01$. Looking at the size of these differences it was found that young subjects in the experimental group on the average had an $8 \mathrm{~m}$ shorter minimum headway compared to the control group. The corresponding result for elderly subjects was $6 \mathrm{~m}$. The minimum headway also differed between age groups in that elderly subjects on the average had a minimum headway of $50 \mathrm{~m}$, while younger subjects on the average had $42 \mathrm{~m}$ as their minimum headway.

\section{Maximum headway}

Figure 3 shows the relevant results concerning the subjects' maximum headway.

A two-way ANOVA showed only a significant effect of AGE, $F(1,36)=7.25, p=0.01$. Looking at the size of the maximum headways, it can be noted that the elderly subjects' (experimental plus control group) mean maximum headway was $125.0 \mathrm{~m}$. The corresponding results for young subjects' was $96.6 \mathrm{~m}$.

\section{Average headway}

Figure 4 shows the relevant results for the subjects' average headway.

A two-way ANOVA showed only a significant difference of AGE, $F(1,36)=6.78, p=0.01$. On the average, elderly drivers (experimental plus control group) had a mean headway of $85.5 \mathrm{~m}$. The corresponding value for younger drivers was $62.9 \mathrm{~m}$. Thus, the prediction was supported, meaning that the subjects did not compensate for an increased reaction time by increasing their headway.

\section{Lateral position}

It was predicted that the subjects' ability to follow the road in an optimal way should be negatively affected by the mobile telephone task. Therefore, the subjects' lateral position in connection to the

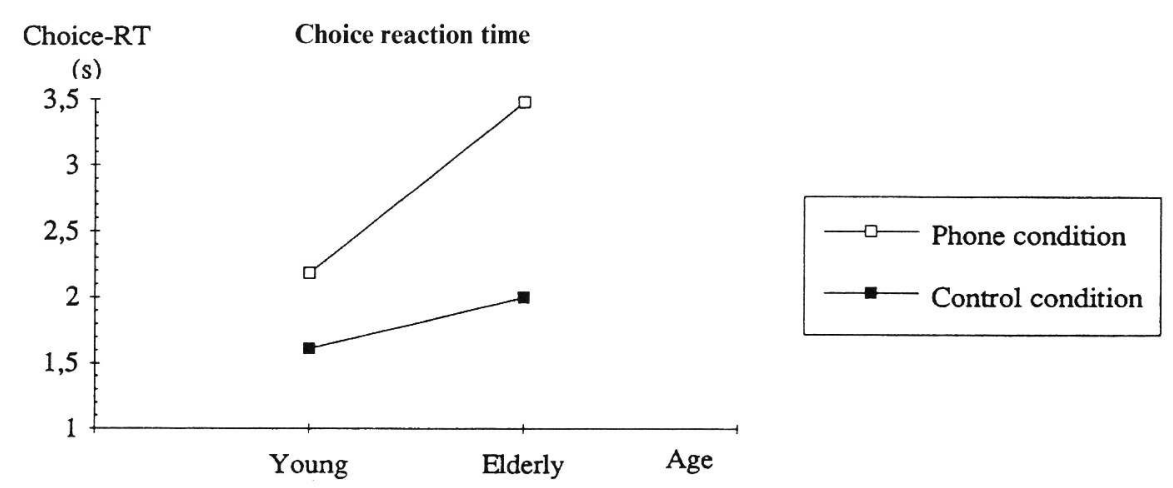

Fig. 1. Choice reaction time as a function of experimental condition and age. 


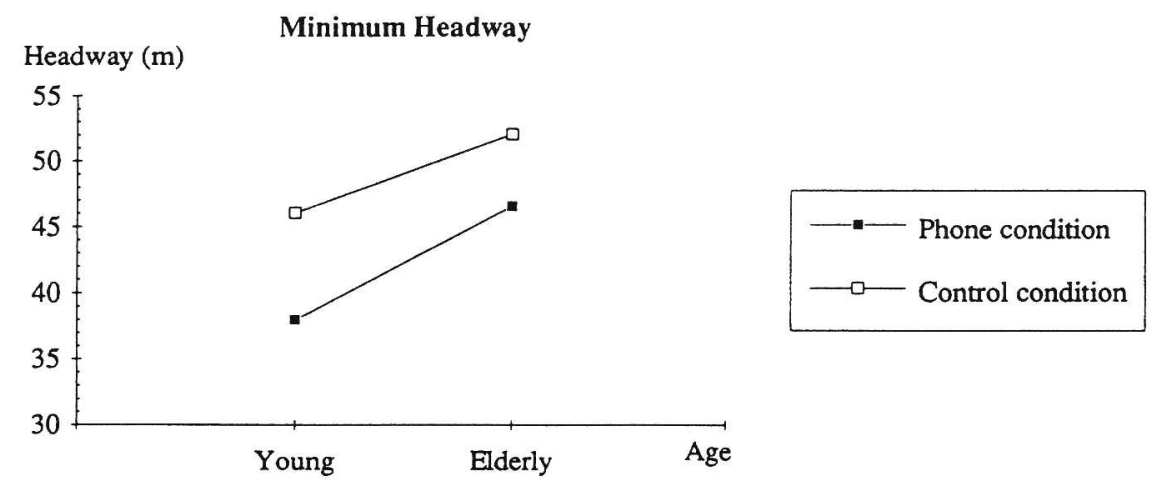

Fig. 2. Minimum headway as a function of experimental condition and age.

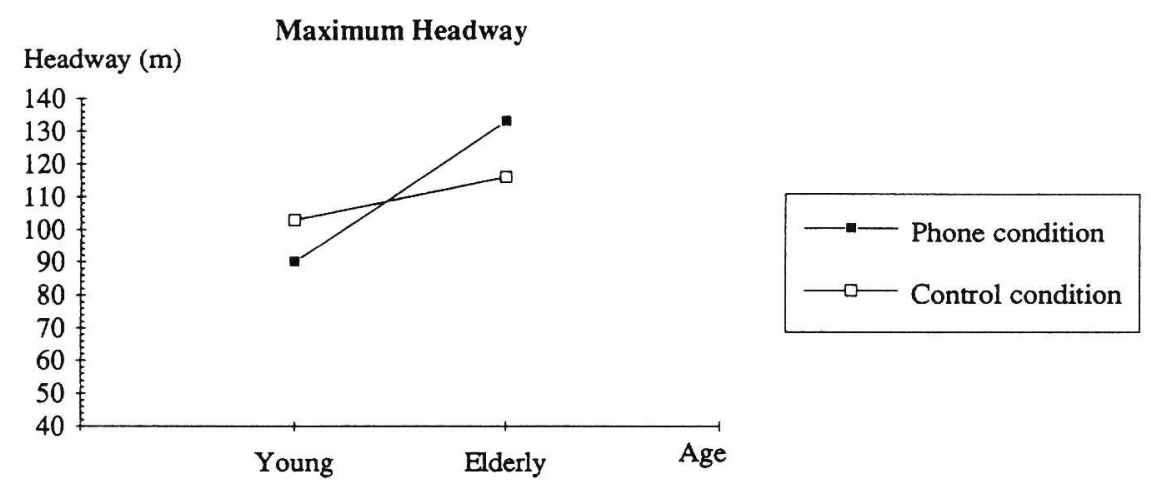

Fig. 3. Maximum headway as a function of experimental condition and age.

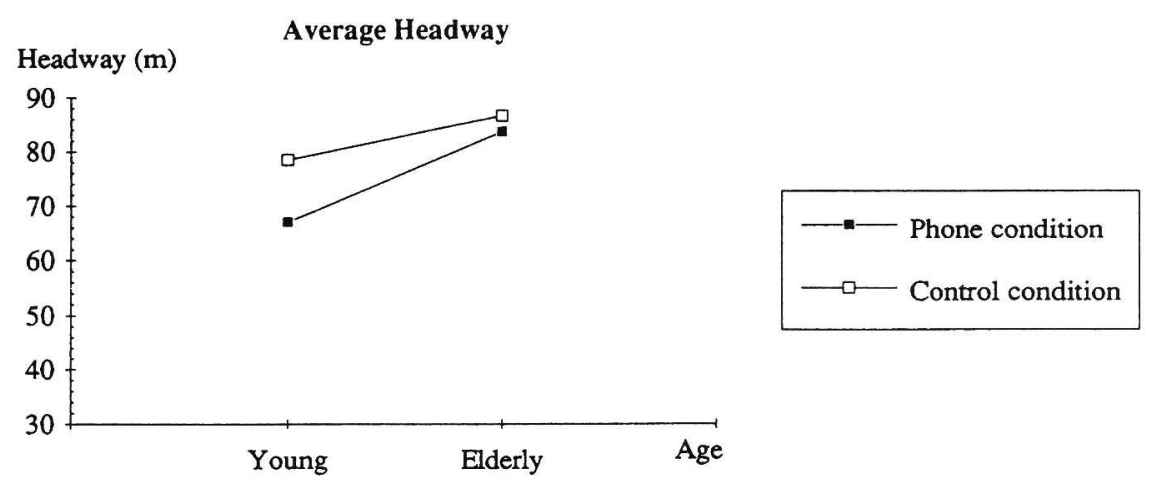

Fig. 4. Average headway as a function of experimental condition and age.

telephone tasks was analysed in a number of ways. Firstly, the subjects' mean lateral position and variation in lateral position, from the moment the mobile telephone rang and $10 \mathrm{sec}$ onwards. The $10 \mathrm{sec}$ phase covers the time during which a driver must distribute his/her visual attention between the mobile telephone (activate the handsfree function) and driving. For the control groups the corresponding measures were taken. A mean value of each subject's lateral position summarized over all eight telephone tasks was calculated. A two-way ANOVA performed on these mean values showed no significant difference between exper- imental and control groups. A mean value of each subjects variation in lateral position for the same period was also calculated. A two-way ANOVA failed to show any difference between experimental and control groups. Secondly, the mean lateral position and variation in lateral position were analysed for a period of $80 \mathrm{sec}$, starting from the moment the mobile telephone rang and covering the entire telephone task. For the control groups the corresponding measures were taken. Two two-way ANOVAs failed to show any significant difference. Thus, the hypothesis was not supported. 


\section{Workload}

Using the NASA-RTLX (Byers et al. 1989), the hypothesis that a mobile telephone conversation should lead to increased workload was tested. Separate two-way ANOVAs were performed on the ratings of the different workload components. Table 1 shows the results relevant to the hypothesis.

Table 1 shows significant differences between experimental and control groups for all workload components in the NASA-RTLX, with the exception of "physical demand". The subjects in the experimental groups rated mental demand, time pressure, effort, and frustration as higher compared to the subjects in the control groups. The subjects in the control groups rated their performance as higher than the subjects in the experimental groups. The only main effect of age was that the younger subjects rated their effort significantly higher compared to the elderly subjects. Thus the prediction was supported.

\section{The telephone task}

The subjects' performance on the working memory span test was analysed in two ways. The number of correct judgements of sentence sensibility and the number of correctly recalled last words were used as inputs to the analysis. Table 2 shows the results.

Table 1. Results of ANOVAs performed on the NASARTLX subscale ratings

\begin{tabular}{lcccc}
\hline Factor & Source & df & $F$ & $P$ \\
\hline Mental demand & RTI & 1,36 & 31.30 & 0.0001 \\
Physical demand & - & - & - & - \\
Time pressure & RTI & 1,36 & 14.23 & 0.0006 \\
Performance & RTI & $\mathbf{1 , 3 6}$ & 14.48 & 0.0005 \\
Effort & AGE & 1,36 & 5.52 & 0.0244 \\
Effort & RTI & 1,36 & 8.08 & 0.0073 \\
Frustration & RTI & 1,36 & 4.35 & 0.0442 \\
\hline
\end{tabular}

Table 2. Performance on the telephone task as a function of age

\begin{tabular}{|c|c|c|c|c|}
\hline & \multicolumn{2}{|c|}{ Correct judgements } & \multicolumn{2}{|c|}{ Correct recalls } \\
\hline & Young & Elderly & Young & Elderly \\
\hline & 39 & 38 & 25 & 19 \\
\hline & 35 & 25 & 10 & 7 \\
\hline & 39 & 38 & 13 & 3 \\
\hline & 37 & 38 & 19 & 32 \\
\hline & 38 & 35 & 25 & 7 \\
\hline & 37 & 29 & 2 & 7 \\
\hline & 38 & 32 & 17 & 19 \\
\hline & 40 & 35 & 16 & 21 \\
\hline & 32 & 38 & 20 & 18 \\
\hline & 39 & 38 & 29 & 19 \\
\hline Mean & 37.40 & 34.60 & 17.60 & 15.20 \\
\hline SD & 2.25 & 4.34 & 7.57 & 8.47 \\
\hline
\end{tabular}

As can be seen from Table 2 there were small differences between young and elderly subjects both in the number of correct judgements and in the number of correctly recalled last words. $t$-Tests (two tailed) failed to show any statistically significant difference for any of the measures.

\section{DISCUSSION}

Alm and Nilsson (1994) and Nilsson and Alm (1991) showed that performing a telephone task during driving increased simple reaction time by 0.385 for young, and $0.439 \mathrm{sec}$ for elderly subjects, when the subjects were driving on a road where the tracking demands were low. In these studies the subjects knew that only one event could occur, and also what to do when it occurred. In this study a more complex driving task was used, including interaction with other road users. More than one event could occur, and more than one action was supposed to be performed in response to what happened in the traffic situation. This led to an increase in reaction time, for young subjects from 0.385 to $0.560 \mathrm{sec}$. For the elderly subjects the increase was from 0.439 to $1.460 \mathrm{sec}$. In this context it must be noted that the variation in choice reaction time between the elderly subjects was very large. The fact that someone is equal to, or more than 60 years old, does not necessarily mean that she or he reacts slowly.

One way to compensate for an increased reaction time in a car following situation is to increase the headway to the lead vehicle. In this study we could not find any evidence at all of compensation by an increased headway. This result can be interpreted in at least two ways. Firstly, that the subjects were unaware of the impact of the mobile telephone task on their ability to react quickly, and therefore saw no reason to increase their headway. To learn that one's reaction time is longer during concurrent driving and telephoning, a driver must be confronted with similar situations a sufficient number of times, with and without using the telephone. The driver must also be able to notice, remember, and compare the reaction time in the different situations. Since the mobile telephone is a rather new device it can be argued that people in general have not had time to learn its effects on their driving behaviour. The feedback a driver gets on his or her behaviour may also be distorted. The traffic system is often forgiving, and a mistake from one driver is quite often compensated for by another driver, which means that errors may sometimes not even detected. Another way of learning the effects of mobile telephone use on reaction time is to learn it from others. For instance, mass media, companies who are selling mobile telephones, or other 
drivers. In these cases it is doubtful whether correct learning is very likely. Mass media have only recently taken up the topic of traffic safety and mobile telephones. Companies selling mobile telephones will probably concentrate on the positive aspects of the product. Most drivers like to be seen as skilled drivers (Svenson 1981) and probably have a tendency to keep their mistakes for themselves.

A second explanation to why the subjects did not increase their headway during the telephone task is that the subjects already had a headway large enough to compensate for a decease in reaction time. Looking at the group of young subjects in the experimental group, we can notice that they had an average headway of $57.1 \mathrm{~m}$, and an average speed level of $87.5 \mathrm{~km} / \mathrm{hr}$. If a "worst case situation" is assumed, meaning that the lead vehicle would brake very hard $\left(7 \mathrm{~m} / \mathrm{sec}^{2}\right)$ and come to a complete stop after $3.47 \mathrm{sec}$ average subject would not be able to stop his/her car in time, given a mean reaction time equal to the recorded $2.19 \mathrm{sec}$. Looking at the elderly subjects, the situation is about the same. The average speed level for elderly subjects in the experimental group was lower, $77.4 \mathrm{~km} / \mathrm{hr}$. The mean headway was $84.31 \mathrm{~m}$, that is longer than the headway for young subjects. But the average reaction time was $3.48 \mathrm{sec}$. A car in front of them, braking with $7 \mathrm{~m} / \mathrm{sec}^{2}$, would need $3.07 \mathrm{sec}$ to come to a complete stop. In other words, the average subject in this group would hit the leading vehicle before $s / h e$ was able to initiate a braking manoeuvre. Thus, a reasonable conclusion is that the headway of younger and elderly subjects was not large enough to include the increased risk caused by an increased reaction time.

It was predicted that the use of the mobile telephone should also lead to an increased variability in lateral position. This hypothesis was not supported. The reason may have to do with the difference between the driving task in this study and the one in Alm and Nilsson (1994). In this study there was a frequent stream of oncoming vehicles, which more or less may have forced the subjects to be careful. The tracking demands of the driving task were also rather low, and the presumed distracting effects of a mobile telephone task may not have had a chance to show up. In this context it must be noted that the effect on the drivers' tracking ability found in the earlier study was not dramatic, and was more pronounced when the tracking demands of the driving task were high.

It was predicted that a mobile telephone task would also lead to an increased level of mental workload. The hypothesis was supported. It is often argued that car driving is a self-paced task where the driver, within reasonable limits, can control the demands of the driving task. From this study it was found that the drivers did not control the demands of the driving task, at least not in such a way that their workload was kept constant. An increased workload can have different consequences, depending upon a number of factors. The relation between level of workload and level of risk in a traffic situation is probably complex (non linear), but it seems safe to assume that a very high level of workload can produce negative effects. A driver's stress level may increase, leading to "tunnel vision" or a narrowing of attention. This can have a positive effect on traffic safety if the driving task demands a very focused type of attention (following another vehicle), and a negative effect if the driving task demands a more global type of attention (driving in intersections). Extreme levels of workload may also mean that the processing resources for new information are limited. Such a limitation may not have any effect at all in highly regulated traffic situations, more or less free from unpredictable events. On the contrary it may have a dramatic effect in traffic situations fairly free from regulations and where unpredictable events can occur. Given the results of this study, it seems that driving in a car-following situation, and using the mobile telephone concurrently, may increase the risk of an accident if something unexpected happens.

One interesting question is why the subjects in the study behaved in such a way that their risk increased. As mentioned earlier, one possible explanation is that the subjects were unaware of the effect of the secondary task on their ability to react quickly. Another possibility is that the subjects overestimated their ability to react quickly. A third possibility is that choice of headway has become a rather fixed behavioural pattern, a habit, for skilled drivers. In all these cases it may be possible to correct this kind of increased risk taking by training and/or education. Another possibility, based on the use of modern information technology, is to develop an intelligent help-system which can inform or assist the driver in keeping an optimal distance to a lead vehicle, during telephoning.

Finally, some comments on the use of a driving simulator in this study. The use of an advanced driving simulator can raise the question about the external validity of simulator studies. Subjects participating in a simulator study are not exposed to any real danger, and can consequently act in a different manner compared to a real life situation. This is undoubtedly true, but our experience is that this can be prevented by instruction to the subjects. By stressing the importance of behaving in the same way as when driving a real car, a clear majority of the subjects seem to be able to do that. Car driving is also an overlearned task, especially for the experi- 
enced drivers that were used in all our three studies. Thus it seems reasonable to expect a strong transfer of behaviour from a real driving situation to a simulator situation, given that the simulator has a high level of realism.

Acknowledgements-This study was performed as a part of the DRIVE project V 1017 BERTIE, Changes in Driver Behaviour due to the Introduction of RTI systems. We are indebted to the members of the BERTIE consortium for providing a stimulating working environment. We are also indebted to the simulator group at VTI, especially Håkan Jansson, for assistance with the design, data collection, and running of the study. Helen Petterson helped us to recruit and run subjects. Christina Ruthger checked the language. Inger Bengtsson helped us with the coding of some data. A number of colleagues have given valuable comments on an earlier version of this article. In particular we are grateful for comments and suggestions from Roger Johansson VTI, and from two unknown reviewers. This study was financially supported by the Swedish Transport Research Board (TFB), and the Swedish National Road Administration (SNRA).

\section{REFERENCES}

Alm, H.; Nilsson, L. Changes in driver behaviour as a function of handsfree mobile telephones. Accid. Anal. Prev. 26: 441-451; 1994.

Baddeley, A. D.; Logie, R.; Nimmo-Smith, I.; Brerefon, N. Components of fluent reading. J. Memory Lang. 24: 119-131; 1995.
Byers, J. C.; Bittner, Jr, A. C.; Hill, S. G. Traditional and raw task load index (TLX) correlations: are paired comparisons necessary? Advances in Industrial Ergonomics and Safety I. London: Taylor \& Francis; 1989.

Evans, L. Traffic Safety and the Driver. New York: Van Nostrand Reinhold; 1991.

Evans, L.; Wasielewski, P. Do accident involved drivers exhibit riskier everyday driving behavior? Accid. Anal. Prev. 14: 57-64; 1982.

Hart, S. G.; Staveland, L. E. Development of NASA_TLX (Task Load Index): results of empirical and theoretical research. In: Hancock, P. A.; Meshkati, N., editors. Human Mental Workload. Amsterdam: Elsevier Science; 1988.

Nilsson, L. The VTI Driving Simulator. DRIVE Project V1017 BERTIE, Report No. 24; 1989.

Nilsson, L.; Alm, H. Effects of mobile telephone use on elderly drivers' behaviour-including comparisons to younger drivers' behaviour. DRIVE project V 1017 BERTIE, Report No. 176; 1991.

Nordmark, S.; Jansson, H.; Lidström, M.; Palmkvist, G. A moving base driving simulator with wide angle visual system. VTI särtryck 106A, Swedish Road and Traffic Research Institute; 1986.

Nordmark, S.; Jansson, H.; Lidström, M.; Palmkvist, G. The VTI driving simulator-recent developments. Swedish Road and Traffic Research Institute; 1988.

Svenson, O. Are we less risky and more skilful than our fellow drivers? Acta Psychol. 47: 143-148; 1981. 


\section{d Swedish National Road and Transport Research Institute}

RESEARCH FOR MOBILITY

The Swedish Road and Transport Research Institute has laboratories and know-how for advanced research commissions in transport and welfare economics, road safety, vehicles and the environment. It also has research capabilities for the construction, operation and maintenance of roads and railways. 